\title{
Observation of ceramic cracking during quenching
}

\author{
Yingfeng Shao ${ }^{1,2}$ | Fan Song ${ }^{1,2}$ | Boyang Liu ${ }^{3}$ | Wei Li ${ }^{1}$ | Long Li ${ }^{1,2}$ | Chiping Jiang
}

\author{
${ }^{1}$ State Key Laboratory of Nonlinear Mechanics, \\ Institute of Mechanics, Chinese Academy of \\ Sciences, Beijing, China \\ ${ }^{2}$ School of Engineering Science, University of \\ Chinese Academy of Sciences, Beijing, China \\ ${ }^{3}$ College of Ocean Science and Engineering, \\ Shanghai Maritime University, Shanghai, China \\ Correspondence \\ Yingfeng Shao, State Key Laboratory of \\ Nonlinear Mechanics, Institute of Mechanics, \\ Chinese Academy of Sciences, Beijing, China. \\ Email: shaoyf@lnm.imech.ac.cn \\ Funding information \\ National Natural Science Foundations of China, \\ Grant/Award Number: 11102208, 11572326, \\ $11232013,11472285$.
}

\begin{abstract}
It is difficult to observe the thermal shock cracking in real time, so the measurement of the crack after thermal shock is considered as an alternative method. This paper proposes a new experimental method which can exhibit the thermal shock cracking in real time by water quenching of translucent ceramic and high-speed imaging. The crack propagation is captured, and the crack growth rate is calculated. The results confirm the previous theoretical predictions of crack propagation under thermal shock. This paper expands the research on understanding the failure mechanisms of ceramic materials in thermal shock.
\end{abstract}

\section{K E Y W O R D S}

alumina, cracks/cracking, thermal shock/thermal shock resistance

\section{1 | INTRODUCTION}

When a thermal gradient causes different parts of an object to expand by different amounts, the differential expansion can be understood in terms of stress. At some point, the stress will exceed the strength of the material, and cause a crack. This phenomenon is known as thermal shock. Up to now, various aspects of the thermal shock have been studied, one of the most important, the determination of thermal shock cracking for ceramics. ${ }^{1-16}$

Numerous theoretical studies on thermal shock crack propagation and crack length hierarchy phenomena have been reported, including the principle of energy, ${ }^{10}$ the energy release rate, ${ }^{11}$ the energy minimization, ${ }^{12,13}$ the nonlocal failure model, ${ }^{14}$ and the variational model etc. ${ }^{15-16}$ These works verified and complemented each other, and promoted the studies on thermal shock cracking phenomenon of ceramics. In the experiment, the main research is to investigate the crack after thermal shock by staining or direct observation. ${ }^{1-6}$ There are few real-time observations of thermal shock cracking. The possible reason is that the real-time observation of thermal shock cracking is difficult. ${ }^{14}$ The ceramic is not only subject to thermal shock, but also observed for in situ cracking. The goal of this paper is to develop an experimental method for the realtime observation of thermal shock cracking.
For this purpose, we design a special apparatus for the thermal shock of semitransparent ceramic sheet. We use a high-speed camera to capture the real-time thermal shock cracking and calculate the crack propagation rate. At the same time, we compare the results with previous calculations.

\section{2 | EXPERIMENTAL PROCEDURE}

\section{1 | Materials processing}

The translucent ceramic studied here was made of highpurity $99.5 \% \mathrm{Al}_{2} \mathrm{O}_{3}$ powder (particle size $0.5 \mu \mathrm{m}$; Xiongdi Material Co., Ltd., Jiyuan, China), which was carefully stabilized in an azeotropic mixture of butanone/alcohol at 66/ 34 (volume ratio) using phosphate ester (LFH, Zhongjie Chemical Co., Ltd., Qingdao, China), polyvinyl butyral and butyl benzyl phthalate as dispersant, binder, and plasticizer, respectively. After tape casting and drying in air for 6 hour, the green tapes were calcined at $1100^{\circ} \mathrm{C}$ in air, and subsequently sintered at $1850^{\circ} \mathrm{C}$ for 2 hour in hydrogen. The bulk density of the ceramic was about $3.96 \mathrm{~g} / \mathrm{cm}^{3}$ by measuring its dimension and weight.

The specimen surface was polished with $\mathrm{SiC}$ papers and diamond suspensions, and then it was thermally etched at $1500^{\circ} \mathrm{C}$ for 0.5 hour in air. After that, the surface 


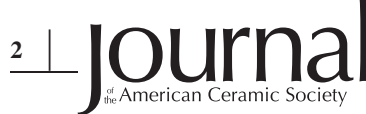

microstructure was observed by the scanning electron microscope (SEM, JSM-7500F, Jeol, Tokyo, Japan), as shown in Figure 1. Using the mean linear intercept method, the mean grain size at the surface was measured to be about $18.9 \mu \mathrm{m}$.

\section{2 | Thermal shock test}

In order to ensure the formation of two-dimensional penetrating crack, ceramic sheets with dimensions of $0.4 \mathrm{~mm}$ in thickness, $10 \mathrm{~mm}$ in width, and $50 \mathrm{~mm}$ in length were employed to investigate the crack patterns during thermal shock by the water-quenching method. To prevent access of the coolant to the side faces $(10 \mathrm{~mm} \times 50 \mathrm{~mm})$, the sheet was stacked with two quartz glass slabs and was bound up with inconel wires $(0.4 \mathrm{~mm}$ in diameter; Shanghai Jinchang Alloy Co., Ltd., Shanghai, China) positioned $<4 \mathrm{~mm}$ from both the ends of the slabs, as shown in Figure 2.

The specimen was heated to a preset temperature at a rate of $10^{\circ} \mathrm{C} / \mathrm{min}$ and held at this temperature for 30 minute. After that, the sample is quickly taken out and put on a specific location of a table which has been positioned by focusing within 5 seconds, then the spray head upon the sample begins to spray deionized water of $20^{\circ} \mathrm{C}$ at a rate of about $5 \mathrm{~mL} / \mathrm{s}$. Water flows through the flume on quartz slabs, so the test sheet with the narrow upper surface $(0.4 \mathrm{~mm} \times 50 \mathrm{~mm})$ is subjected to water quenching. Note that, the critical temperature difference of quartz glass $\left(\sim 1200^{\circ} \mathrm{C}\right)$ is much higher than that of alumina $\left(\sim 230^{\circ} \mathrm{C}\right)$, so there will be no crack in the quartz glass affecting the experimental results. The high-speed camera (Fastcam SA$\mathrm{X} 2$, Photron, Tokyo, Japan) is used to capture images during the thermal shock process at 10000 frames per second

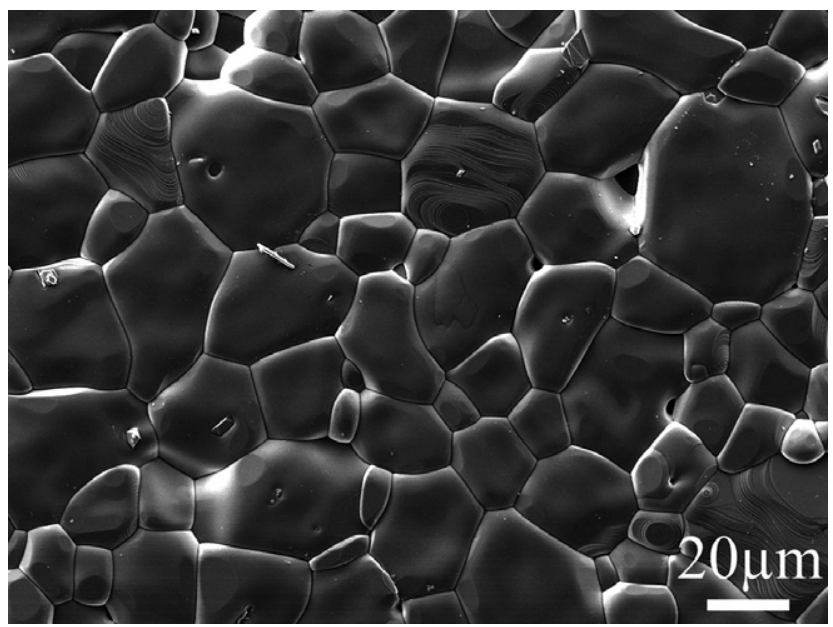

F I G URE 1 SEM micrograph showing the surface morphology of the alumina. The mean grain size was measured to be about $18.9 \mu \mathrm{m}$ by linear intercept method

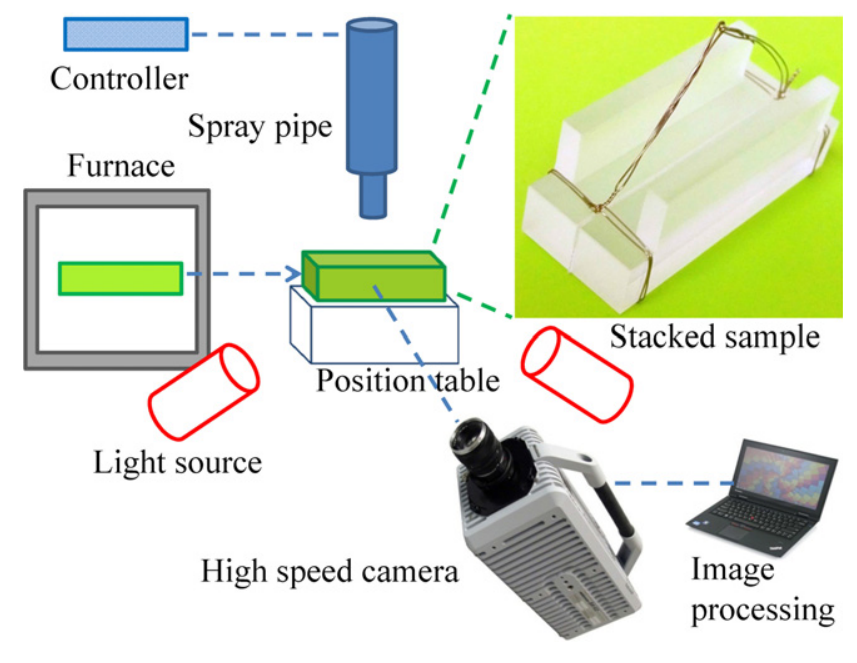

F I G URE 2 Scheme of the apparatus for real-time observation of the ceramic cracking during quenching [Color figure can be viewed at wileyonlinelibrary.com]

with a resolution of $1024 \times 512$ Pixels, as shown in Figure 2. In this way, we can observe the initiation and growth of cracks due to the refraction and reflection of the light from the interface of the crack during thermal shock. From the series of recorded images in experiment, we can obtain the crack speed by the slope of the crack length curves per millisecond.

\section{3 | RESULTS AND DISCUSSION}

The captured images of ceramic crack initiation and propagation under quenching temperature difference of $280^{\circ} \mathrm{C}$ are revealed in Figure $3 \mathrm{~A}-\mathrm{E}$. We can see that it can be divided into two stages. In stage I, when the water drops to the sample, a number of the thermal shock cracks initiate and gradually propagate at an approximately equal spacing, as shown in Figure 3A,B. This should be caused by the stresses induced by a thermal gradient exceeding the strength of the materials, so the random distribution of the initial surface defects produce multiple cracks.

At around $80 \mathrm{~ms}$, about every second crack continues to propagate, whereas the other cracks gradually stop. This phenomenon is called the crack hierarchy, which could be caused by the gradual release of the strain energy with the crack growth that cannot continue to support the simultaneous propagation of all cracks. Then, the evolution of crack patterns continues to stage II. In this stage, about half of the cracks with similar spacing continue to propagate until the strain energy cannot support simultaneous propagation of any propagating cracks. The whole process of thermal shock cracking is only a few seconds, which has been accurately predicted by many researchers. ${ }^{10-16}$ When we increase the severity of thermal shock, such as increasing 


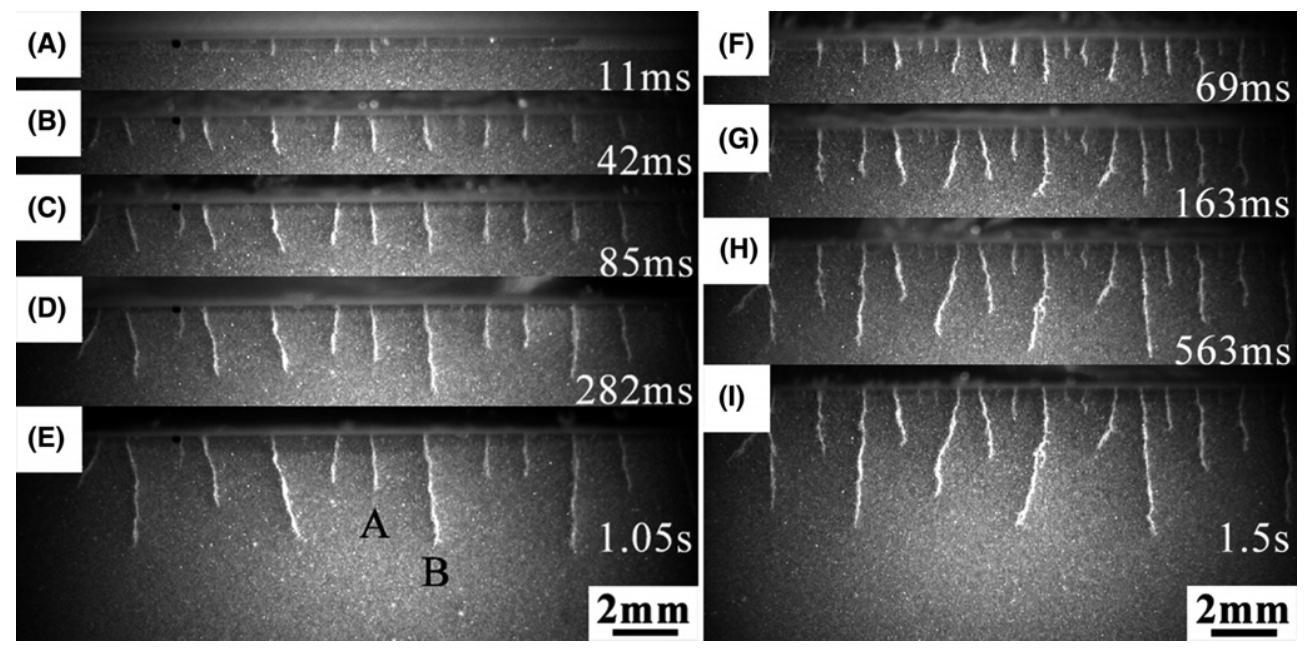

F I G U RE 3 The captured images of ceramic cracks initiation and propagation under thermal shock at quenching temperature difference of (A)-(E) $280^{\circ} \mathrm{C}$; and (F)-(I) $430^{\circ} \mathrm{C}$

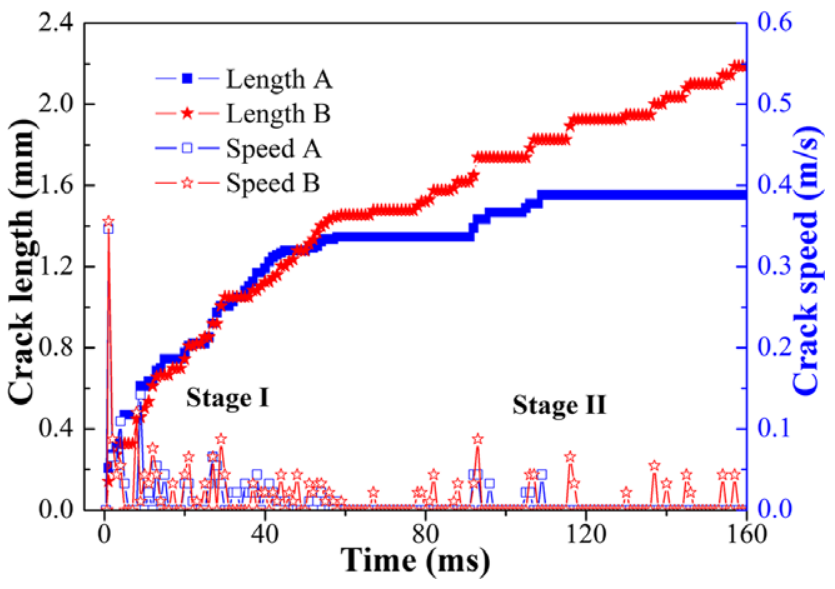

F IG U RE 4 The length and speed of the propagating cracks A and B vs time in Figure 3(E) [Color figure can be viewed at wileyonlinelibrary.com]

the temperature difference, crack hierarchy phenomenon appears again, ie every fourth crack continues to propagate, and other cracks stop, as shown in Figure 3F-I. It is very similar to the stage II.

The length and speed of the propagating cracks $\mathrm{A}$ and $\mathrm{B}$ in Figure 3E vs time are plotted in Figure 4. At the beginning, the thermal shock cracks propagate very rapidly, which is about $0.4 \mathrm{~m} / \mathrm{s}$, and then it becomes slowly, until crack hierarchy. Crack A gradually stops propagating, while crack B continues growing. In stage II, the speed of crack B shows a sudden increase, which is about $0.1 \mathrm{~m} / \mathrm{s}$. It is probably because the strain energy supports only half of the cracks propagation. After that, the propagation speed gradually decreases until stop.

From the observation point of view, the crack speed is less than $1 \mathrm{~m} / \mathrm{s}$, which is far less than the Rayleigh wave speed of alumina $(3 \mathrm{~km} / \mathrm{s}) .{ }^{17}$ Therefore, the crack propagation in thermal shock can be considered as a quasistatic process, which confirms the assumption of previous studies. ${ }^{10-16}$ In addition, the crack has several pauses of a few milliseconds in the propagation process, as shown in Figure 4, which should be correspond to the time of stress redistribution. When a crack moves forward a small distance, the stress of the position is relaxed, and after a few milliseconds of stress redistribution, the crack meets the fracture criterion and propagates again, depending on the nature of the temperature profile.

\section{CONCLUSIONS}

We perform the water quench test using a specially designed apparatus that guarantees the observation of ceramic cracking in real time. The periodical and hierarchical characteristics of the crack patterns are captured which has been accurately predicted by many researchers. As a result, the speed of crack growth is less than $1 \mathrm{~m} / \mathrm{s}$, far less than the Rayleigh wave speed of alumina. Therefore, the crack propagation in thermal shock can be considered as a quasistatic process.

\section{ACKNOWLEDGMENTS}

This work was supported by the National Natural Science Foundations of China (grant. 11102208, 11572326, 11232013 and 11472285).

\section{REFERENCES}

1. Song F, Meng SH, Xu XH, Shao YF. Enhanced thermal shock resistance of ceramics through biomimetically inspired nanofins. Phys Rev Lett. 2010;104:125502, 4pp. 
2. Shao YF, Xu XH, Meng SH, Bai GH, Jiang CP, Song F. Crack patterns in ceramic plates after quenching. J Am Ceram Soc. 2010;93:3006-3008.

3. Li DY, Li WG, Wang RZ, Fang DN. The effects of water entry postures on the thermal shock behavior of alumina. Int J Appl Ceram Technol. 2016;13:56-60.

4. Shao YF, Zhang Y, Xu XH, Zhou ZL, Wei L, Liu BY. Effect of crack pattern on the residual strength of ceramics after quenching. J Am Ceram Soc. 2011;94:2804-2807.

5. Vandeperre LJ, Kristofferson A, Carlström E, Clegg WJ. Thermal shock of layered ceramic structures with crack-deflecting interfaces. J Am Ceram Soc. 2001;84:104-110.

6. Schneider GA, Petzow G. Thermal shock testing of ceramics - a new testing method. J Am Ceram Soc. 1991;74:98-102.

7. $\mathrm{Lu}$ TJ, Fleck NA. The thermal shock resistance of solids. Acta Mater. 1998;46:4755-4768.

8. Fellner M, Supancic P. Thermal shock failure of brittle materials. Key Eng Mater. 2002;223:97-106.

9. Bermejo R, Llanes L, Anglada M, Supancic P, Lube T. Thermal shock behavior of an $\mathrm{Al}_{2} \mathrm{O}_{3} / \mathrm{ZrO}_{2}$ multilayered ceramic with residual stresses due to phase transformations. Key Eng Mater. 2005;290:191-198.

10. Bazant ZP, Ohtsubo H, Aoh K. Stability and post-critical growth of a system of cooling or shrinkage cracks. Int J Fract. 1979;15:443-456.

11. Bahr HA, Weiss HJ, Maschke HG, Meissner F. Multiple crack propagation in a strip caused by thermal shock. Theor. Appl. Fract. Mech. 1988;10:219-226
12. Jenkins DR. Optimal spacing and penetration of cracks in a shrinking slab. Phys Rev E. 2005;71:056117, 8pp.

13. Jiang CP, Wu XF, Li J, Song F, Shao YF, Xu XH. A study of the mechanism of formation and numerical simulations of crack patterns in ceramics subjected to thermal shock. Acta Mater. 2012;60:4540-4550.

14. Li J, Song F, Jiang CP. Direct numerical simulations on crack formation in ceramic materials under thermal shock by using a non-local fracture model. J Eur Ceram Soc. 2013;33:2677-2687.

15. Bourdin B, Marigo JJ, Maurini C, Sicsic P. Morphogenesis and propagation of complex cracks induced by thermal shocks. Phys Rev Lett. 2014;112:014301, 5pp.

16. Sicsic P, Marigo JJ, Maurini C. Initiation of a periodic array of cracks in the thermal shock problem: a gradient damage modeling. J Mech Phys Solids. 2014;63:256-284.

17. Zavattieri PD, Espinosa HD. Grain level analysis of crack initiation and propagation in brittle materials. Acta Mater. 2001;49:4291-4311.

How to cite this article: Shao Y, Song F, Liu B, $\mathrm{Li} \mathrm{W,} \mathrm{Li} \mathrm{L,} \mathrm{and} \mathrm{Jiang} \mathrm{C.} \mathrm{Observation} \mathrm{of} \mathrm{ceramic}$ cracking during quenching. J Am Ceram Soc. 2016;00:1-4. doi:10.1111/jace.14674. 